\title{
Keratinocyte-derived follistatin regulates epidermal homeostasis and wound repair
}

\author{
Maria Antsiferova ${ }^{1}$, Jennifer E Klatte ${ }^{2,3}$, Enikö Bodó ${ }^{2}$, Ralf Paus ${ }^{2,4}$, José L Jorcano ${ }^{5}$, Martin M Matzuk ${ }^{6,7,8}$, \\ Sabine Werner ${ }^{1}$ and Heidi Kögel ${ }^{1}$
}

Activin is a growth and differentiation factor that controls development and repair of several tissues and organs. Transgenic mice overexpressing activin in the skin were characterized by strongly enhanced wound healing, but also by excessive scarring. In this study, we explored the consequences of targeted activation of activin in the epidermis and hair follicles by generation of mice lacking the activin antagonist follistatin in keratinocytes. We observed enhanced keratinocyte proliferation in the tail epidermis of these animals. After skin injury, an earlier onset of keratinocyte hyperproliferation at the wound edge was observed in the mutant mice, resulting in an enlarged hyperproliferative epithelium. However, granulation tissue formation and scarring were not affected. These results demonstrate that selective activation of activin in the epidermis enhances reepithelialization without affecting the quality of the healed wound.

Laboratory Investigation (2009) 89, 131-141; doi:10.1038/labinvest.2008.120; published online 15 December 2008

KEYWORDS: activin; dermis; epidermis; follistatin; wound healing

Activins are members of the transforming growth factor- $\beta$ family of growth and differentiation factors. They are dimeric proteins, consisting of two activin $\beta$ subunits cross-linked by a disulfide bridge. The most abundant activin variants are the homodimers activin $\mathrm{A}(\beta \mathrm{A} \beta \mathrm{A})$ and activin $\mathrm{B}(\beta \mathrm{B} \beta \mathrm{B})$, as well as the heterodimer activin $\mathrm{AB}(\beta \mathrm{A} \beta \mathrm{B}){ }^{1}$. They exert their biological functions by binding to a heteromeric complex of type I and type II receptors, which are all transmembrane receptor serine/threonine kinases. ${ }^{2}$ The biological activity of activins is regulated by the secreted glycoprotein follistatin (Fst), which sequesters activins and thus inhibits their biological activities. ${ }^{3}$

Activins were initially discovered as inducers of folliclestimulating hormone release, but by now, a wide variety of different functions of activins have been described. They are crucial regulators of organ development, and abnormal activin expression is associated with various diseases. ${ }^{1,4}$

Several studies unraveled important functions of activin in the skin. Among the many developmental defects Fst-null mice show impaired skin, whisker and hair follicle development. ${ }^{5-7}$ As these mice die within hours of birth they cannot be used to study the role of the activin/Fst system in mature skin. Interestingly, we and others previously demonstrated important roles of activins, in particular of activin A, in tissue repair after acute or chronic injury as well as in human inflammatory disease. ${ }^{8}$ Expression of activin, in particular of the $\beta$ A subunit, is strongly induced in healing wounds of mice and humans. ${ }^{9}$ This upregulation is of functional importance, as transgenic mice overexpressing Fst in the epidermis showed a severe delay in wound repair. ${ }^{10}$ On the other hand, transgenic mice overexpressing activin $\mathrm{A}$ in the epidermis were characterized by a strong acceleration of the wound healing process. ${ }^{11}$ Activin $\beta \mathrm{A}$ mRNA levels in the skin of these mice are more than 100-fold higher compared to controls (our unpublished data), and excessive activin diffuses to the dermis and the stromal compartment of skin wounds and enters the blood. ${ }^{11}$ As a result, transgenic mice also developed an extended granulation tissue, followed by excessive scarring. ${ }^{11}$ Therefore, the potent activation of the stroma by activin is detrimental for the outcome of the repair process.

On the basis of these results, we speculated that selective activation of activin in keratinocytes may enhance the wound

\footnotetext{
${ }^{1}$ Department of Biology, Institute of Cell Biology, ETH Zürich, Zürich, Switzerland; ${ }^{2}$ Department of Dermatology, University of Lübeck, Lübeck, Germany; ${ }^{3}$ Department of Molecular Medicine, Max-Planck Institute for Biochemistry, Martinsried, Germany; ${ }^{4}$ School of Translational Medicine, University of Manchester, Manchester, UK; ${ }^{5}$ Department of Cell and Molecular Biology, Centro de Investigaciones Energéticas, Medioambíentales y Technológicas, Madrid, Spain; ${ }^{6}$ Department of Pathology, Baylor College of Medicine, Houston, TX, USA; ${ }^{7}$ Department of Molecular and Cellular Biology, Baylor College of Medicine, Houston, TX, USA and ${ }^{8}$ Department of Molecular and Human Genetics, Baylor College of Medicine, Houston, TX, USA

Correspondence: Dr S Werner, PhD, Institute of Cell Biology, Department of Biology, ETH Zürich, Hönggerberg, HPM D42, Zürich CH-8092, Switzerland.

E-mail: Sabine.werner@cell.biol.ethz.ch
}

Received 2 July 2008; revised 2 October 2008; accepted 16 October 2008 
healing process without the negative side effects on the stroma. To test this hypothesis we generated mice lacking Fst in keratinocytes. The loss of this inhibitory protein should enhance the biological activity of activin in the epidermis and hair follicles. Although the free activin is still expected to diffuse to the dermis, the amount of diffusible activin is most likely much lower compared to the levels seen in the activinoverexpressing transgenic mice. The characterization of the keratinocyte-specific Fst knockout (ko) mice allowed us to determine the role of endogenous Fst in normal and wounded skin.

\section{MATERIALS AND METHODS Mice}

Mice with a deletion of the six-exon Fst gene ${ }^{5}$ and mice homozygous for the K5-Cre transgene ${ }^{12}$ were mated to generate offspring heterozygous for the mutant Fst allele and hemizygous for the K5-Cre transgene (Fst wild type (wt)/ko $\mathrm{K}$-Cre ${ }^{+}$). These mice were mated with mice homozygous for the floxed (fl) Fst allele $F s t^{f l o x 13}$ to obtain conditional Fst ko mice ( $F s t$ ko/fl K5-Cre ${ }^{+}$). K5-Cre transgenic mice were of C57BL/6N genetic background, Fst-null mice and Fst ${ }^{f l o x}$ mice were of mixed C57BL/6/129SvEv genetic background. Genotyping was performed by PCR using primers for the Fst-null allele (5'-GGTGGGAAATGTCACCTGAT- ${ }^{\prime}, \quad 5^{\prime}$-CGGTGG ATGTGGAATGTGT- $3^{\prime}$ ) and Cre recombinase $\left(5^{\prime}\right.$-AACATGC TTCATCGTCGG- $3^{\prime}, \quad 5^{\prime}$-TTCGGATCATCAGCTACACC- $3^{\prime}$ ) or the bovine $\mathrm{K} 5$ promoter ( $5^{\prime}$-CCAGGTGGAGTCACAGG ATT-3', 5'-TGTGCCAGAGGGGAAAATAG-3'). Successful recombination of the fl Fst allele was verified by Southern blot analysis as previously described. ${ }^{13}$ All animal experiments were performed with permission from the local veterinary authorities (Kantonales Veterinäramt, Zürich, Switzerland).

\section{Wounding and Preparation of Wound Tissue}

Mice (8-10 weeks old) were anesthetized by intraperitoneal injection of ketamine $(75 \mathrm{mg} / \mathrm{kg}) / x y l a z i n e ~(5 \mathrm{mg} / \mathrm{kg})$. Four full-thickness excisional wounds of $5 \mathrm{~mm}$ diameter were generated on the back of mice by excising the skin and the rodent-specific subcutaneous muscle panniculus carnosus as described previously. ${ }^{14}$ Wounds were left uncovered and harvested at different time points after injury. They were excised, including $2-3 \mathrm{~mm}$ of the adjacent back skin, bisected, fixed in 4\% PFA in phosphate-buffered saline (PBS) or $1 \%$ acetic acid/95\% ethanol at $4{ }^{\circ} \mathrm{C}$ overnight and embedded in paraffin according to standard procedures. Alternatively, complete wounds including $1 \mathrm{~mm}$ of the margins were excised, immediately frozen in liquid nitrogen and pools of at least eight wounds were used for RNA isolation.

\section{RNA Isolation and RNase Protection Assay}

Mouse tail skin was incubated in $2 \mathrm{M} \mathrm{NaBr}$ for $30 \mathrm{~min}$ at $37^{\circ} \mathrm{C}$. Epidermis was subsequently separated from dermis, snap-frozen in liquid nitrogen and stored at $-80^{\circ} \mathrm{C}$. RNA
Table 1 Sequences of primers used for quantitative RT-PCR

\begin{tabular}{lll}
\hline Name & Forward primer & Reverse primer \\
\hline Follistatin & agggaaagtgtatcacaaagt & gagttgcaagatccagaatg \\
Activin $\beta \mathrm{A}$ & ggagaacgggtatgtggaga & acaggtcactgccttccttg \\
Activin $\beta \mathrm{B}$ & cgcaggacacctgtacgtc & atgtgtctcttcaccgcctc \\
Myostatin & aaacccatgaaagacggtaca & attcagcccatcttctcctg \\
GDF-11 & aaacccatgaaagacggtaca & attcagcccatcttctcctg \\
BMP-2 & gtttggcctgaagcagagac & cgtcactggggacagaactt \\
BMP-4 & atgagggatctttaccggct & tttatacggtggaagccctg \\
BMP-6 & ctccttgaaccgcaagagtc & tgtggggagaactccttgtc \\
BMP-7 & tccagggaaagcataattcg & cttggaaagatcaaaccgga \\
GAPDH & tcgtggatctgacgtgccgcctg & caccaccctgttgctgtagccgtat \\
RPII & ttcacggtactgggcattga & tgtgctgctgcttccataag \\
\hline
\end{tabular}

isolation and RNase protection assay were carried out as described. ${ }^{15,16}$ A $307 \mathrm{bp}$ fragment corresponding to nucleotides $780-1086$ of the murine Fst $\mathrm{CDNA}^{10}$ and a $120 \mathrm{bp}$ fragment corresponding to nucleotides 566-685 of the murine glyceraldehyde-3-phosphate dehydrogenase $(\mathrm{GAPDH}) \mathrm{cDNA}$ were used as templates.

\section{Quantitative Real-Time RT-PCR}

RNA was isolated by acid guanidinium thiocyanate-phenolchloroform extraction as described previously, ${ }^{15}$ followed by additional purification using the RNeasy MinElute Cleanup kit (Qiagen) according to the manufacturer's instructions. Reverse transcription was performed with the iScript cDNA Synthesis kit (Bio-Rad). Relative gene expression was determined using the Roche LightCycler 480 System and SYBR Green I Master Mix (Roche Diagnostics) as recommended by the manufacturer. Target mRNA levels were normalized to the levels of GAPDH and RNA polymerase II polypeptide A mRNAs. Specific primers were designed using Primer3 software. ${ }^{17}$ Primer sequences are listed in Table 1.

\section{Culture of Primary Mouse Keratinocytes}

Murine epidermal keratinocytes were isolated as described previously $^{18}$ with some modifications. Briefly, adult mice (3-8 weeks) were killed, shaved and sequentially washed in iodine solution, then in distilled water followed by $70 \%$ ethanol and distilled water again. The skin was removed, placed in PBS containing $50 \mu \mathrm{g} / \mathrm{ml}$ gentamycin, $200 \mathrm{U} / \mathrm{ml}$ penicillin, $200 \mu \mathrm{g} / \mathrm{ml}$ streptomycin and $5 \mu \mathrm{g} / \mathrm{ml}$ fungizone (all from Gibco), and all of the subcutaneous tissue was scraped off. The skin was then incubated in $0.8 \%$ trypsin for $1 \mathrm{~h}$ at $37^{\circ} \mathrm{C}$. Subsequently, the epidermis was separated from the dermis and stirred in defined keratinocyte serum free medium (Invitrogen, Basel, Switzerland) containing 10\% FCS, $200 \mathrm{U} / \mathrm{ml}$ penicillin, $200 \mu \mathrm{g} / \mathrm{ml}$ streptomycin and $10^{-10} \mathrm{M}$ cholera toxin for $1 \mathrm{~h}$ at room temperature. Cells were filtered 
through a $70 \mu \mathrm{m}$ nylon cell strainer (BD Falcon), centrifuged and resuspended in fresh medium (see above) supplemented with $10 \mathrm{ng} / \mathrm{ml}$ EGF. They were then seeded onto fibronectin/ collagen-coated dishes $(1 \mathrm{mg} / \mathrm{ml} \mathrm{BSA}, 20 \mathrm{mM}$ HEPES, $30 \mu \mathrm{g} / \mathrm{ml}$ Vitrogen collagen solution (Cohesion, USA), $10 \mu \mathrm{g} / \mathrm{ml}$ fibronectin) at a density of $10^{5}$ cells per $\mathrm{cm}^{2}$ of surface area. Primary keratinocytes were grown at $34^{\circ} \mathrm{C}$ with $5 \% \mathrm{CO}_{2}$.

\section{Preparation of Protein Lysates and Western Blot Analysis}

Primary keratinocytes from wt and Fst mutant mice were lysed in lysis buffer containing $50 \mathrm{mM}$ Tris- $\mathrm{HCl}, \mathrm{pH} 7.4$, $150 \mathrm{mM} \mathrm{NaCl}, 1 \mathrm{mM}$ ethylenediaminetetraacetic acid, $1 \%$ NP-40, $0.5 \mathrm{mM}$ AEBSF, $10 \mu \mathrm{g} / \mathrm{ml}$ aprotinin, $10 \mu \mathrm{g} / \mathrm{ml} \mathrm{leu}-$ peptin, $10 \mu \mathrm{g} / \mathrm{ml}$ pepstatin, $10 \mathrm{mM} \mathrm{NaF}, 1 \mathrm{mM} \mathrm{Na}_{3} \mathrm{VO}_{4}$, $10 \mathrm{mM} \mathrm{Na}{ }_{4} \mathrm{P}_{2} \mathrm{O}_{7}, 20 \mu \mathrm{M}$ phenylarsinoxide. Proteins were separated by sodium dodecylsulfate-polyacrylamide gel electrophoresis under reducing conditions and transferred to nitrocellulose membrane. Antibody incubations were performed in $5 \%$ nonfat dry milk in PBS $/ 0.1 \%$ Tween 20 . A rabbit polyclonal antibody against $\mathrm{Fst}^{19}{ }^{19}$ and a mouse monoclonal antibody against GAPDH (HyTest, Turku, Finland) were used in combination with an alkaline phosphatase detection system (Promega, USA).

\section{Histology and Histomorphometry}

For histological analysis $7 \mu \mathrm{m}$ sections from the middle of the PFA-fixed wounds or from PFA-fixed tail skin were dewaxed, rehydrated and stained using the Masson trichrome method. For morphometrical analysis, the sections were photographed using a Zeiss Axiophot microscope equipped with a HRC camera (Zeiss, Jena, Germany). The length of the migrating epithelial tongue, the area of the hyperproliferative wound epithelium, the area of the granulation tissue and the percentage of wound closure were determined using the Openlab 3.1.5 software (Improvision Ltd, Basel, Switzerland). Epidermal thickness was measured with $50 \mu \mathrm{m}$ increments on Masson trichrome- or hematoxylin and eosin-stained sections of tail and back skin; 5-15 photographs from each section were analyzed; all values were averaged to obtain mean epidermal thickness. Only animals of the same age and sex were used for direct comparison.

\section{Detection of Proliferating Cells by Labeling with 5-Bromo-2'-Deoxyuridine}

Mice were injected intraperitoneally with 5-bromo- $2^{\prime}$-deoxyuridine (BrdU; $250 \mathrm{mg} / \mathrm{kg} \mathrm{BrdU}$ in $0.9 \% \mathrm{NaCl}$ ) and killed $2 \mathrm{~h}$ after injection. $1 \%$ acetic acid/95\% ethanol-fixed sections were incubated with a horseradish peroxidase-conjugated monoclonal antibody directed against BrdU (Roche), and BrdU-positive cells were visualized using 3,3-diaminobenzidine as substrate (Sigma). Counterstaining was performed with hematoxylin and eosin. BrdU-positive cells were counted in 5-15 fields of the epidermis of back or tail skin or in the entire hyperproliferative epithelium of wounds and related to the length of the basement membrane or to the area of wound epidermis, respectively.

\section{Immunofluorescence}

Sections $(7 \mu \mathrm{m})$ from the middle of the $1 \%$ acetic acid/95\% ethanol-fixed wounds or from tail or back skin were deparaffinized, rehydrated, rinsed in PBS, blocked with 12\% BSA and incubated overnight at $4{ }^{\circ} \mathrm{C}$ with the primary antibodies diluted in PBS containing 1\% bovine serum albumin and $0.01 \%$ Nonidet P- 40 . After three 10-min washes with PBS/ $0.1 \%$ Tween 20 , sections were incubated for $1 \mathrm{~h}$ at room temperature with Cy2- or Cy3-coupled secondary antibodies (Jackson ImmunoResearch Laboratory Inc., West Grove, PA, USA), washed, mounted with Mowiol (Hoechst, Frankfurt, Germany), and analyzed with a Zeiss Axioplan fluorescence microscope. The following antibodies were used: a mouse monoclonal antibody directed against keratin 10 (Dako, Glostrup, Denmark), rabbit polyclonal antibodies directed against keratin 14, keratin 6 and loricrin (all from Covance, Princeton, NY, USA), and a rabbit polyclonal antibody against nidogen-1 (kind gift from Dr. R. Fässler, Martinsried, Germany).

\section{Statistical Analysis}

Statistical analysis was performed using the GraphPad Prism4 software package (GraphPad Software Inc., San Diego, CA, USA). Unpaired $t$-test was used for comparison, as the values were normally distributed. When variances were significantly different according to $F$-test, unpaired $t$-test with Welch's correction was used.

\section{RESULTS}

\section{Generation of Mice Lacking Follistatin in Keratinocytes}

Fst is an ubiquitously expressed glycoprotein that binds the different types of activins with high affinity and thereby prevents their binding to type II receptors. ${ }^{20}$ Thus, it acts as a natural antagonist of activin action. In addition, it binds to myostatin growth and differentiation factor (GDF) -8 and the related GDF-11 (bone morphogenetic protein (BMP)-11) and with significantly lower affinity to several other BMPs, including BMP-2, $-4,-6,-7$ and $-15 .{ }^{21-26}$

Fst is expressed in the epidermis and the dermis of mouse skin, and in contrast to activins, its expression is not regulated during wound healing (Hubner et al ${ }^{9}$; Figure 4). To determine the roles of keratinocyte-derived Fst in skin morphogenesis, homeostasis and repair we generated mice lacking Fst in keratinocytes of the epidermis and hair follicles. This was achieved by breeding mice heterozygous for a Fst-null allele (Fst wt/ko) and a transgene that has the Cre recombinase gene under the control of the bovine K5 promoter with mice harboring fl Fst alleles. ${ }^{12,13}$ Mice lacking Fst in keratinocytes (Fst ko/fl $\mathrm{K}_{5}-\mathrm{Cre}^{+}$mice) were born at the expected Mendelian ratio. They were healthy and fertile and appeared macroscopically normal. Fst $\mathrm{ko} / \mathrm{fl} \quad \mathrm{K}^{-} \mathrm{Cre}^{+}$ conditional ko mice will henceforth be called Fst mutant 
mice; control refers to the Fst wt/fl $\mathrm{K} 5-\mathrm{Cre}^{-}$mice. In some experiments Fst ko/fl $\mathrm{K} 5-\mathrm{Cre}^{-}$mice were used as an additional control and they were indistinguishable from $F s t \mathrm{wt} / \mathrm{fl}$ K5-Cre ${ }^{-}$mice. Recombination of the Fst fl allele was controlled by Southern blot analysis using a probe that allows detection of wt, ko, fl and deleted $(\Delta)$ Fst alleles (Figure 1a). The absence of Fst mRNA in keratinocytes of Fst mutant mice was confirmed by RNase protection assay. Consistent with previously published observations ${ }^{19}$ Fst was found to be expressed in both epidermal and dermal compartments of the skin in wt mice. In contrast, mutant mice express Fst in the dermis, but not in the epidermis, indicating efficient deletion of the Fst gene in keratinocytes (Figure 1b). Expression levels of Fst in the dermis were not affected by the epidermal ko and were similar in heterozygous (Fst ko/fl) and wt (Fst wt/fl) mice (data not shown). RNase protection assay and western blot analysis confirmed the absence of Fst mRNA and protein in primary keratinocytes isolated from mutant mice (data not shown and Figure 1c).

\section{No Evident Skin Abnormalities in Newborn Fst Mutant Mice}

It has previously been shown that mice deficient for Fst die within hours of birth. ${ }^{5,7}$ Besides several severe developmental defects, their skin appeared shiny and taut and their whiskers were thin and inappropriately oriented. Histological analysis revealed thickened granular and cornified layers. In addition, interfollicular expression of keratin 6 was detected, indicating a perturbation of normal epidermal development. To determine if these effects are recapitulated in mice with a keratinocyte-specific Fst ko, we analyzed the skin of control and Fst mutant mice at postnatal day 1 (P1).

Fst mutant mice appeared macroscopically normal at this age. Their skin and vibrissae were indistinguishable from those of their wt littermates. The histological and morphometric analysis revealed no increase in epidermal thickness at this time point (Figure 2a and b). Keratin 6 was not expressed in the interfollicular epidermis and keratin 10 was expressed appropriately in the suprabasal layers (Figure 2c).

\section{Lack of Follistatin in Keratinocytes Enhances Keratinocyte Proliferation in the Tail Epidermis of Adult Mice}

Adult Fst mutant mice did not show any macroscopically visible abnormalities of their skin or fur. The only macroscopic phenotype in adult Fst mutant mice was the shorter tail length (mean \pm s.e.m.: control: $6.8 \pm 0.2 \mathrm{~cm}, \quad N=7$; mutant: $5.9 \pm 0.1 \mathrm{~cm}, N=8 ; P=0.0005)$, a phenomenon that had also been observed in mice overexpressing activin in the epidermis ${ }^{11}$ as well as in mice that express only the Fst-315 splice variant but not the Fst-288 variant. ${ }^{7}$ This phenotype results at least in part from necrosis at the tail tip, ${ }^{11,27}$ most likely as a result of impaired tail vascularization. ${ }^{7}$ Histological examination of Masson trichrome- or hematoxylin and eosin-stained sections of back and tail skin of adult
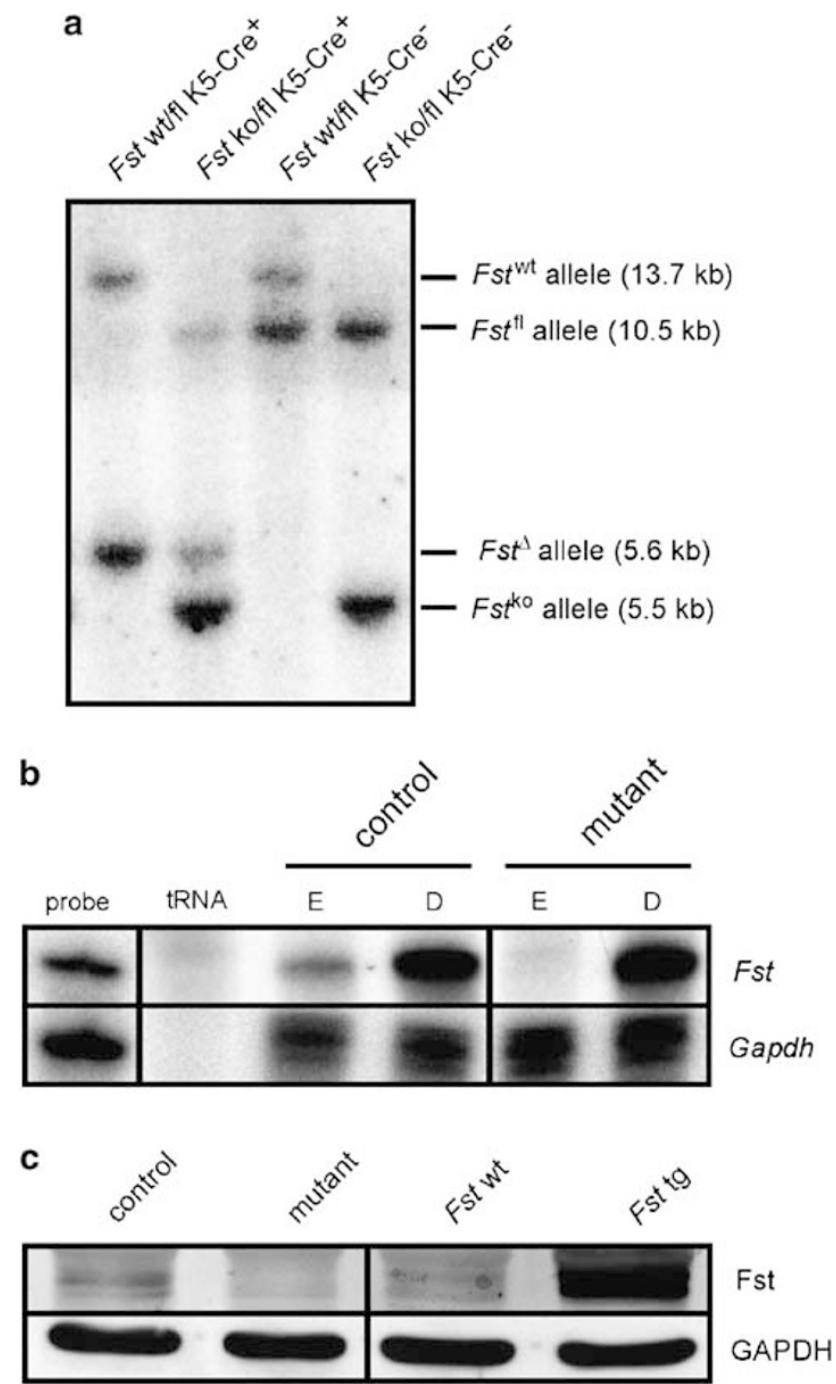

Figure 1 Efficient knockout (ko) of follistatin in the epidermis. (a) Southern blot analysis showing Cre-mediated deletion of the floxed (fl) Fst allele. A $1230 \mathrm{bp} \mathrm{Sacl} /$ Hindlll probe was used to detect wild-type (wt), ko, fl and deleted $(\Delta)$ Fst alleles in genomic DNA digested with Sacl and EcoRI. ${ }^{13}$ (b) Lack of follistatin mRNA in the epidermis is shown by RNase protection assay. Follistatin mRNA is expressed in the dermis and the epidermis of control mice but only in the dermis of Fst mutant mice. Samples of $20 \mu \mathrm{g}$ of total RNA were used for hybridization. The hybridization probes (1000 c.p.m.) served as size markers (probe). tRNA (10 $\mu \mathrm{g}$ ) was used as a negative control. Hybridization of RNA with a GAPDH riboprobe served as a loading control. (c) Western blot analysis showing lack of follistatin in primary keratinocytes isolated from mutant mice. Cell lysates were prepared from primary keratinocytes isolated from mutant (Fst ko/fl $\mathrm{K} 5 \mathrm{Cre}^{+}$) and control (Fst wt/fl K5Cre ${ }^{-}$) littermates. Protein $(100 \mu \mathrm{g})$ was analyzed by western blot analysis with an antibody against follistatin. Protein lysates of primary keratinocytes isolated from mice overexpressing follistatin in the epidermis (Fst $\mathrm{tg})^{10}$ served as a positive control. Expression of follistatin in the wt littermates of these transgenic mice is also shown for comparison (Fst wt).

(8-10 weeks old) Fst mutant mice showed no major differences in the overall skin architecture (Figure 3a). Furthermore, no significant difference in hair follicle cycling was observed at postnatal day 17 , when the hair follicles are in the 
a

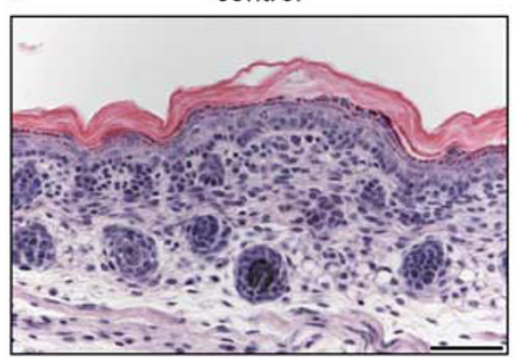

c
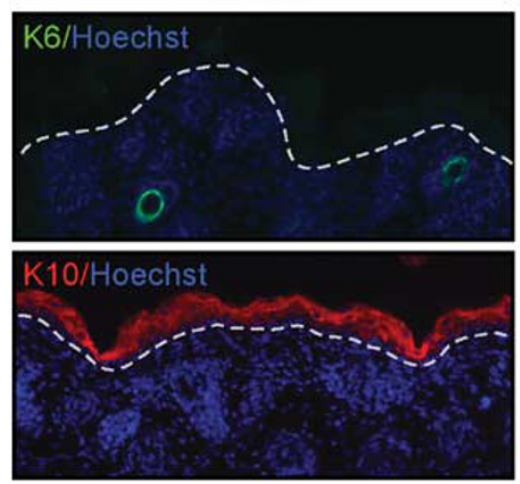
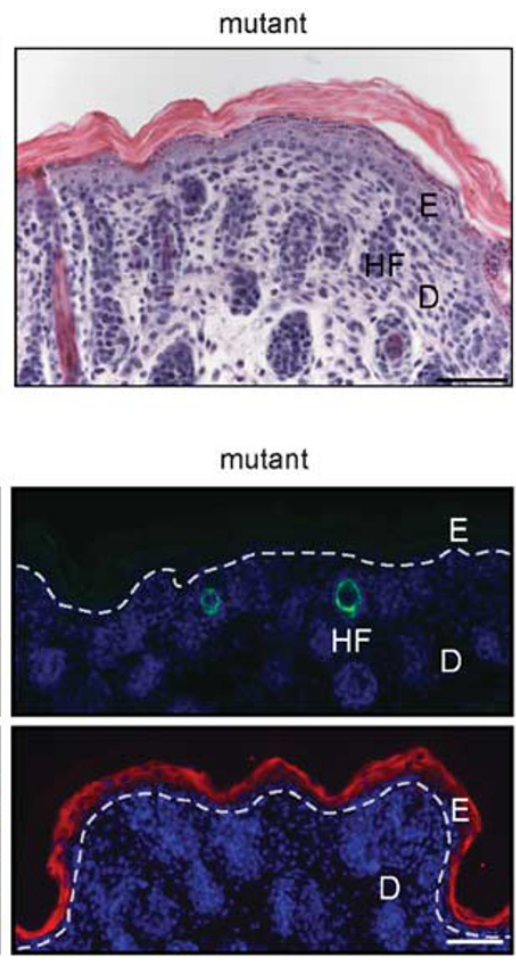

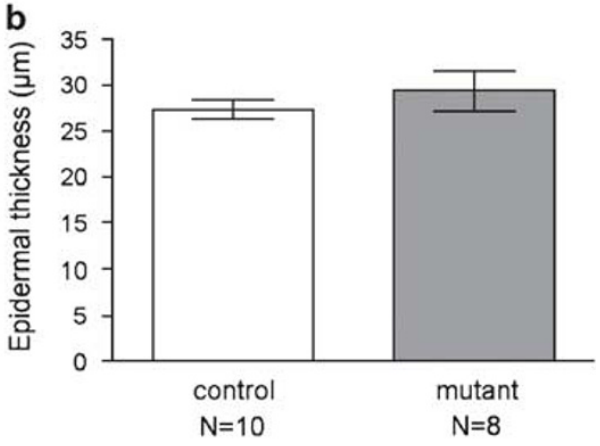

Figure 2 Lack of skin abnormalities in newborn Fst mutant mice. (a) Masson trichrome-stained histological sections of newborn control and Fst mutant skin are shown. (b) Morphometric analysis of tail skin revealed no difference in epidermal thickness. $N=$ number of mice. Results shown are mean \pm s.e.m. (c)

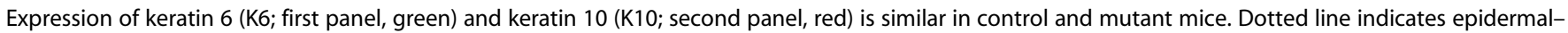
dermal border. (a, c) Bar $=50 \mu \mathrm{m}$. E: epidermis; D: dermis; HF: hair follicle.

first catagen (data not shown). However, the tail epidermis appeared thicker in mutant mice, and this was confirmed by morphometry (Figure 3a, graph). To determine if the increased epidermal thickness results from enhanced keratinocyte proliferation, we determined the number of proliferating keratinocytes in the epidermis using the BrdU incorporation assay. Indeed, we found increased proliferation of tail skin keratinocytes in mutant mice compared to control mice, but proliferation was still restricted to the basal layer of the epidermis (Figure 3b). In addition, basal keratinocytes in the tail epidermis of mutant mice showed abnormal expression of keratin 6 in the interfollicular epidermis (Figure 3c, second panel), reflecting the hyperproliferative phenotype.

Keratin 14, a marker protein for nondifferentiated keratinocytes as well as the early differentiation marker keratin 10 and the late differentiation marker loricrin were normally expressed in the epidermis of tail skin (Figure 3c, first panel and data not shown). This shows that the lack of Fst in keratinocytes does not markedly affect the differentiation program of keratinocytes.

As mice overexpressing activin in keratinocytes were characterized by disturbed expression of the basement membrane proteins tenascin- $\mathrm{C}$ and nidogen, ${ }^{11}$ we wondered if conditional deletion of Fst in keratinocytes would have similar effects. Immunostaining with antibodies against nidogen revealed that basement membrane formation is normal in the skin of Fst mutant mice (Figure 3c, third panel).

\section{Activin is the Major Follistatin Ligand in Healing Skin Wounds}

The activin/Fst system is crucial for the regulation of wound repair. ${ }^{10,11}$ Expression of activin $\beta$ A strongly increases upon wounding, whereas levels of Fst remain unaltered (Hubner et $a l^{9}$; Figure 4). We also analyzed the expression of the other major Fst-binding partners in healing wounds. Activin $\beta \mathrm{B}$ was expressed at much lower levels than activin $\beta$ A (Hubner et $a l^{9}$; data not shown). GDF-11 mRNA was not detectable in normal or injured skin (data not shown). Expression of myostatin was strongly downregulated early after injury (Figure 4). As this gene is mainly expressed in muscle tissue, the observed kinetics most likely reflects the loss of the subcutaneous muscle panniculus carnosus upon wounding. BMP-2, -4, -6 and -7, which are low-affinity binding partners of Fst, were expressed at relatively low levels in normal skin and further downregulated upon skin injury (Figure 4 and data not shown). Expression of BMP-15 was not detectable in normal or wounded skin (data not shown). Taken together, the strong upregulation of the activin $\beta \mathrm{A}$ subunit upon skin injury strongly suggests that activin $\mathrm{A}$ is the major binding partner of Fst in healing skin wounds. 
a

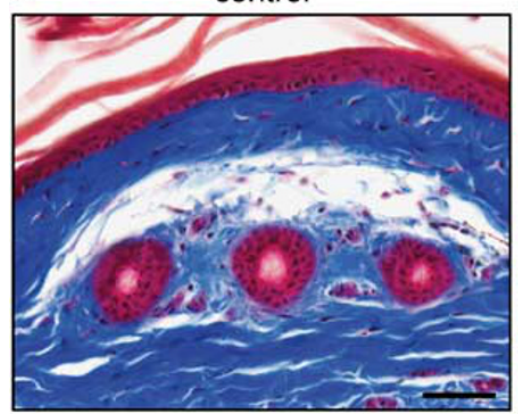

b

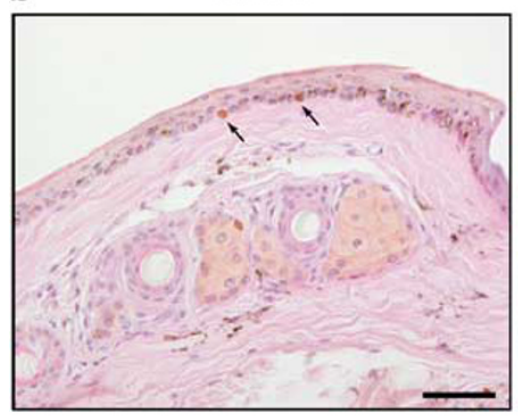

C
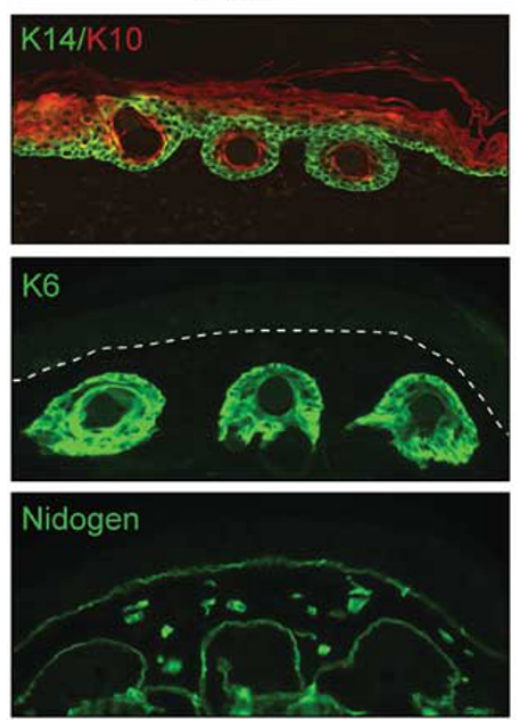

mutant

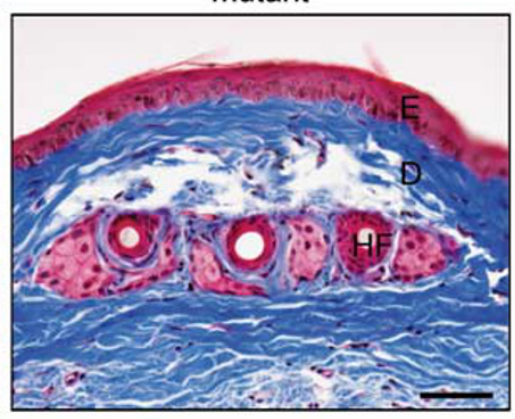

mutant

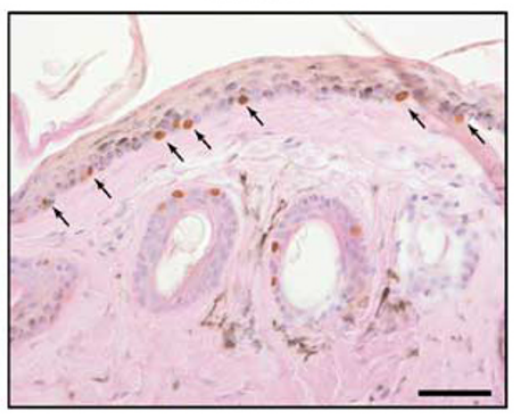

mutant
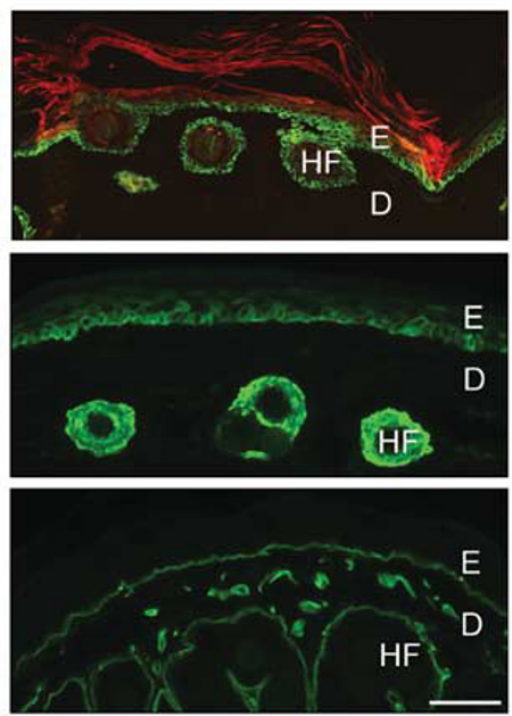
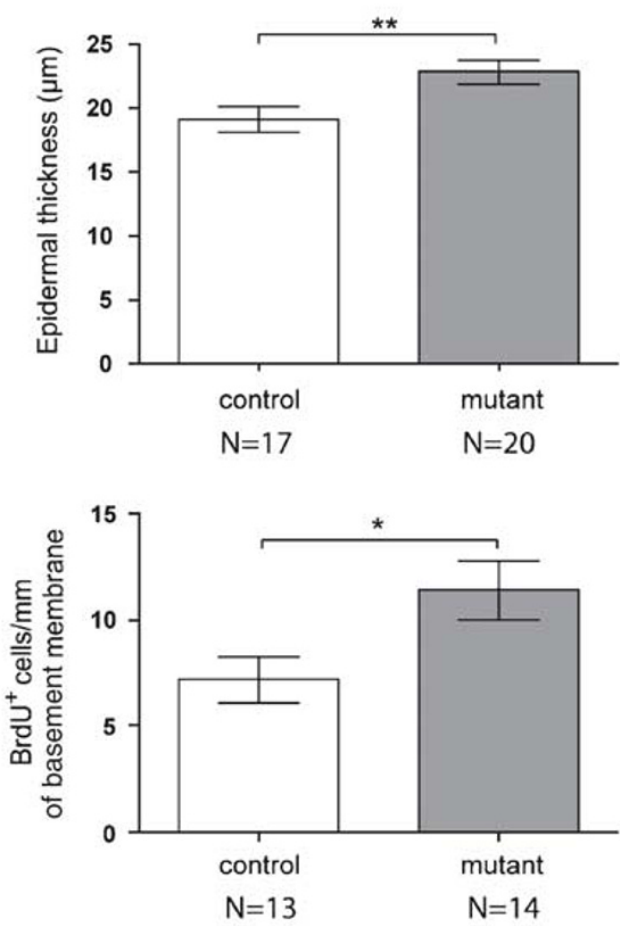

Figure 3 Lack of follistatin in keratinocytes affects skin homeostasis of adult mice. (a) Masson trichrome-stained histological sections of tail skin of adult control and Fst mutant mice are shown. Morphometric analysis of tail skin revealed a significant increase in epidermal thickness in Fst mutant mice $\left.{ }^{* * P}=0.0093\right)$. (b) Increased number of BrdU-positive keratinocytes in tail skin of mutant mice. Arrows indicate stained nuclei. BrdU-positive cells per mm of basement membrane were counted $\left({ }^{*} P=0.0263\right)$. (c) Expression of keratin 14 (K14; first panel, green) and keratin 10 (K10; first panel, red) is similar in control and mutant mice. Fst mutant mice show interfollicular expression of keratin 6 (K6; second panel). Nidogen expression is unaltered in mutant mice (third panel). Dotted line indicates epidermal-dermal border. (a-c) Bar $=50 \mu \mathrm{m}$. E: epidermis; D: dermis; HF: hair follicle. (a, b) $N=$ number of mice. Results shown are mean \pm s.e.m.

Increased Proliferation of Fst Mutant Keratinocytes Early After Skin Injury

The enhanced wound healing seen in mice overexpressing the activin $\beta \mathrm{A}$ subunit in keratinocytes highlights the functional significance of the upregulation of activin expression in healing skin wounds. ${ }^{9,11}$ In these mice, reepithelialization and formation of granulation tissue were enhanced, as the soluble activin can diffuse from the epidermis and hair follicles to the surrounding mesenchyme. Although the enhanced wound healing that is achieved by activin overexpression is 


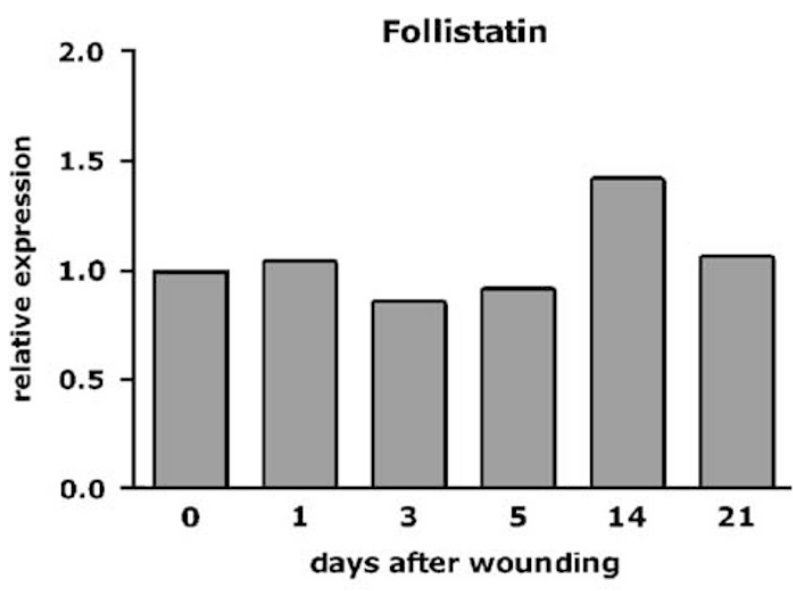

Activin $\beta$ A

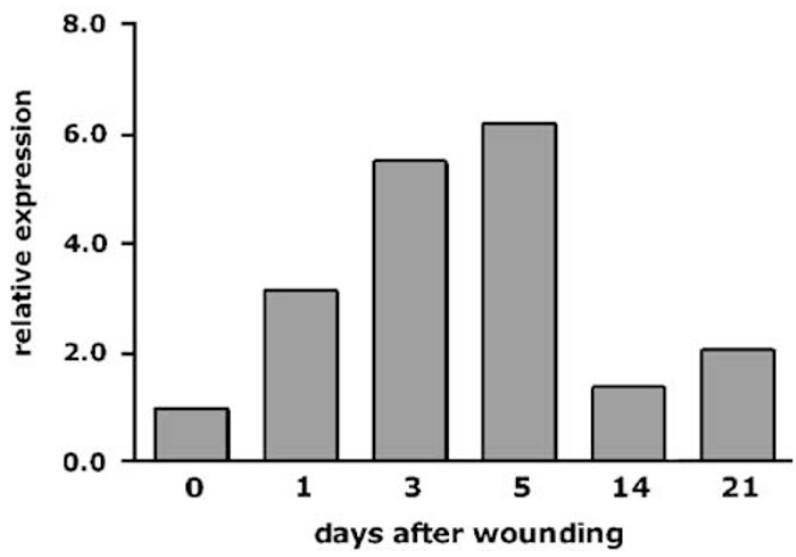

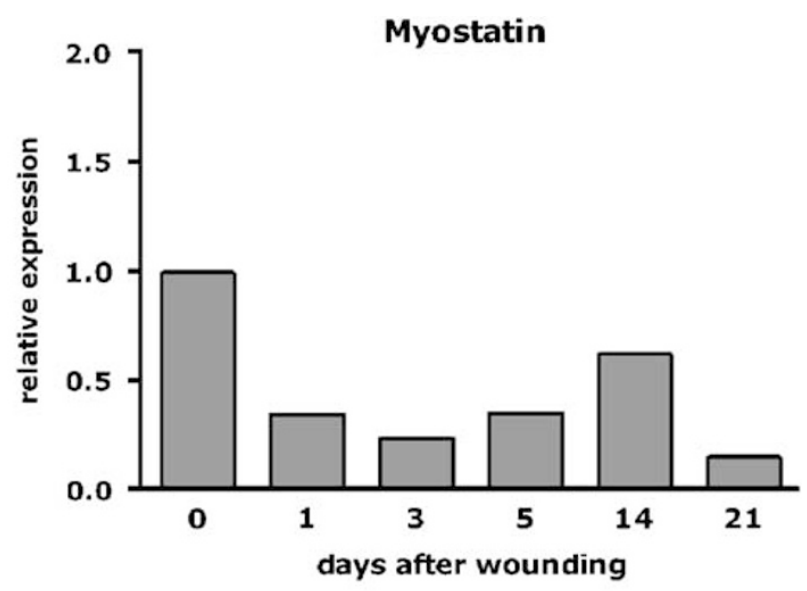

BMP-2

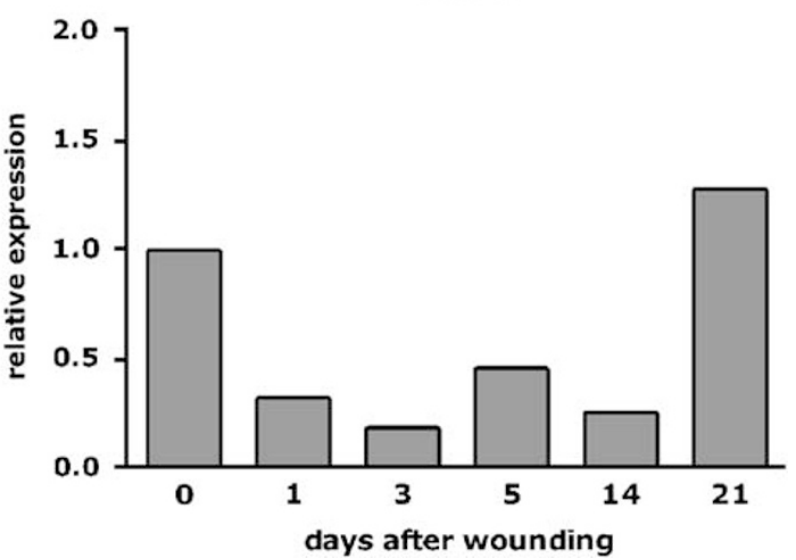

Figure 4 Expression of follistatin and its binding partners in healing skin wounds. RNA was isolated from normal and wounded skin at different stages after injury and analyzed by quantitative RT-PCR for the mRNA levels of follistatin and its binding partners. Expression levels of follistatin, activin $\beta$ A, myostatin and BMP-2 were normalized using GAPDH and RNA polymerase II polypeptide A as reference genes. Expression levels in unwounded skin (0) were set as 1. Each RNA sample was a pool from at least eight wounds.

beneficial, it is unfortunately followed by excessive scarring. ${ }^{11}$ Therefore, we determined if activation of endogenous activin has similar consequences for the wound healing and scarring response.

Reepithelialization of wounds starts within a few hours after injury with migration and hyperproliferation of keratinocytes at the wound edge. ${ }^{28}$ To determine whether proliferation and/or migration of keratinocytes at the wound edge are affected by the Fst mutation, full-thickness excisional wounds were generated on the back of control and Fst mutant mice and analyzed at different time points after injury. Morphometric analysis of Masson trichrome-stained sections of 5-day wounds (Figure 5a) revealed a significant increase in the area of hyperproliferative epithelium in the wounds of mutant mice as compared to those of their wt littermates (Figure 5b). By contrast, the length of the wound epidermis was similar in mice of both genotypes, indicating that migration of keratinocytes is not affected (Figure 5c).
We next determined if the wound edge keratinocytes of these mice show an increased proliferative response to injury, which could account for the increased area of the hyperproliferative epithelium. BrdU incorporation assay was used to quantify proliferation of wound keratinocytes 5 days after wounding (Figure $6 \mathrm{a}-\mathrm{c}$ ). The total number of BrdU-positive cells was similar in control and Fst mutant mice (Figure 6b). Taking into account the increased area of hyperproliferative epithelium, this resulted in a decreased number of proliferating keratinocytes per area (Figure 6c).

If the enlargement of the hyperproliferative epithelium in Fst mutant mice is based on a higher cell division rate, the latter might have occurred during an earlier phase of reepithelialization. Therefore, we analyzed keratinocyte proliferation at an earlier time point-3 days after wounding (Figure $6 \mathrm{~d}-\mathrm{f}$ ). Interestingly, at that stage the number of proliferating keratinocytes was clearly increased in Fst mutant mice, resulting in a significant increase in proliferating keratinocytes per area of hyperproliferative 
a

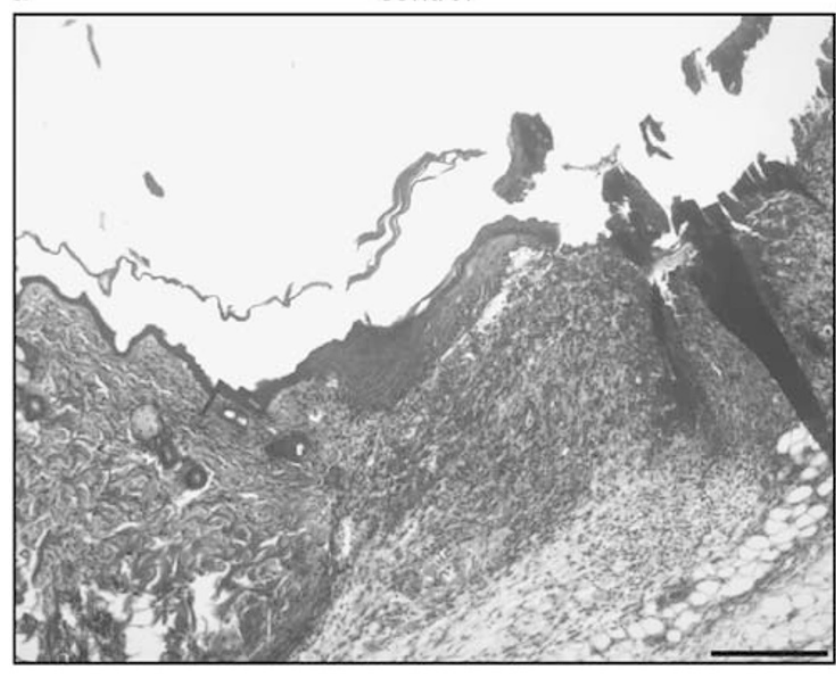

b

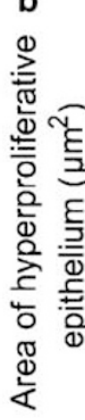

125000

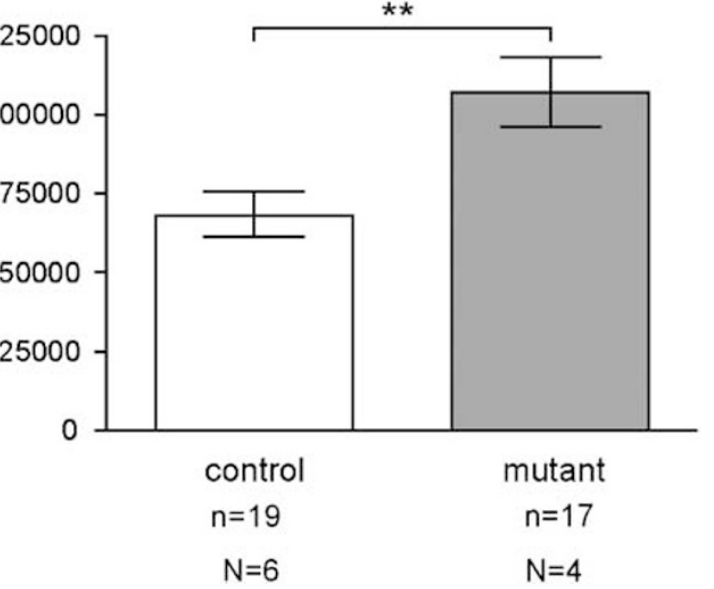

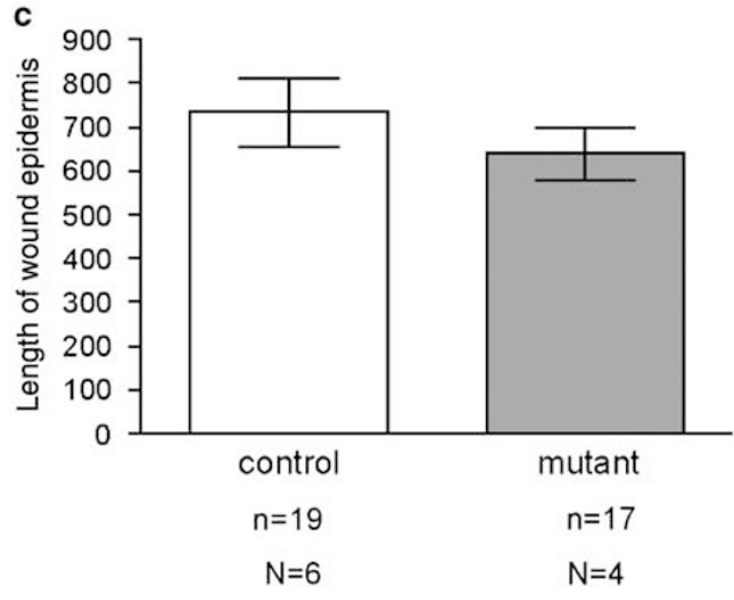

Figure 5 Enlarged area of hyperproliferative epithelium 5 days after wounding in Fst mutant mice. (a) Masson trichrome-stained histological sections of 5-day wounds ( $5 \mathrm{dw}$ ) of control and mutant mice are shown. E: epidermis; D: dermis; HE: hyperproliferative epithelium; GT: granulation tissue; Es: eschar. $\mathrm{Bar}=200 \mu \mathrm{m}$. (b, c) Morphometric analysis of wound healing parameters. The area of the hyperproliferative epithelium in $5 \mathrm{dw}$ is significantly increased in Fst mutant mice $\left(\mathbf{b}:{ }^{*} P=0.0049\right)$, whereas the length of the wound epidermis is similar in control and mutant mice $(\mathbf{c}) . n=$ number of measurements; $N=$ number of mice. Results shown are mean \pm s.e.m.

epithelium (Figure 6e and f). Thus, our results revealed that loss of Fst in keratinocytes enhances keratinocyte proliferation early after injury, resulting in an enlarged area of wound epithelium later on. The analysis of 7- and 14-day wounds did not reveal any differences in the percentage of wound closure between genotypes (data not shown). Therefore, the earlier onset of proliferation upon wounding observed in Fst mutant mice does not result in earlier completion of reepithelialization.

\section{Lack of Follistatin in Keratinocytes does not Affect Granulation Tissue Formation and Scarring}

In spite of the earlier onset of reepithelialization in Fst mutant mice, granulation tissue formation was not obviously affected with regard to size and composition
(Figure 7a and $\mathrm{b}$ ). This result is consistent with the observation that activin-induced stimulation of granulation tissue and scar formation is most likely mediated by activin action on stromal cells. ${ }^{27}$ At 13 and 20 days after injury, wounds were completely reepithelialized, and keratin 14, keratin 10 and loricrin were appropriately expressed (data not shown). The area of late granulation tissue/scar tissue was similar in control and mutant mice (Figure 7b). Thus, the amounts of bioactive activin that are available in normal and wounded skin in the absence of keratinocytederived Fst seem to be sufficient to stimulate reepithelialization. However, they are obviously insufficient to enhance granulation tissue formation. Most importantly, they allow acceleration of the early wound repair process without enhancement of scarring. 
a

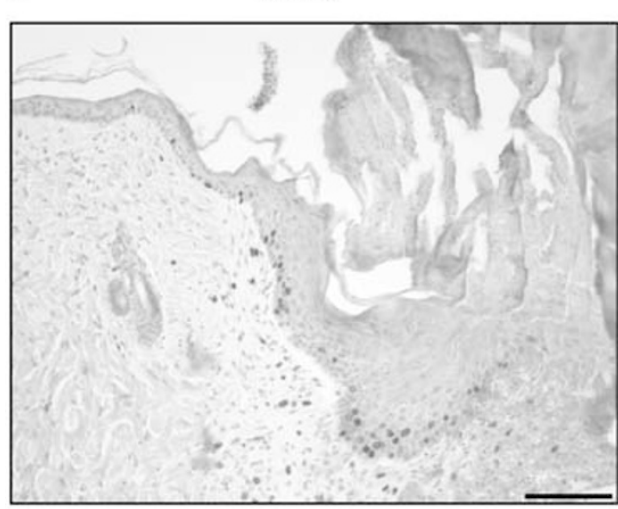

mutant

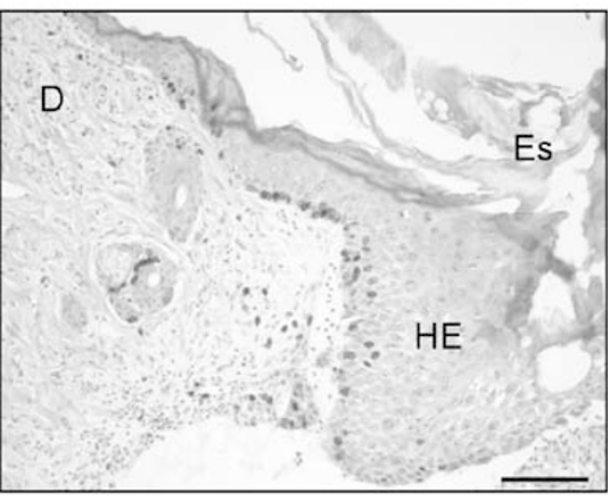

b

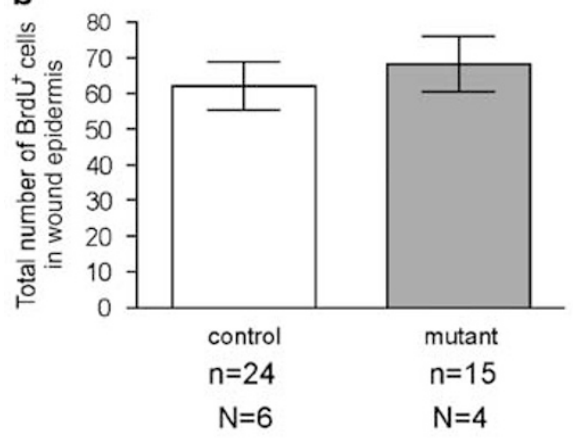

$\mathrm{N}=6$

control
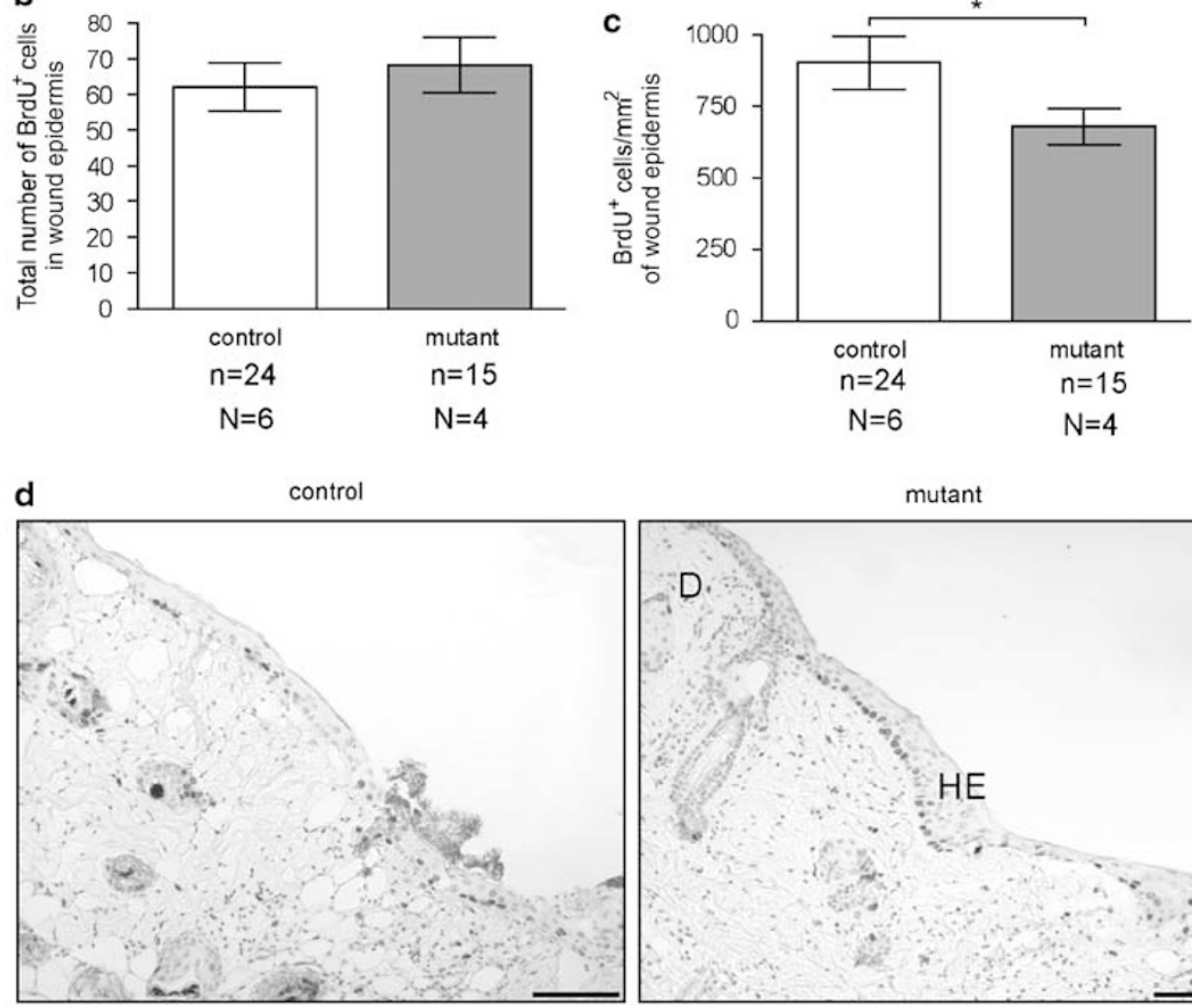

mutant

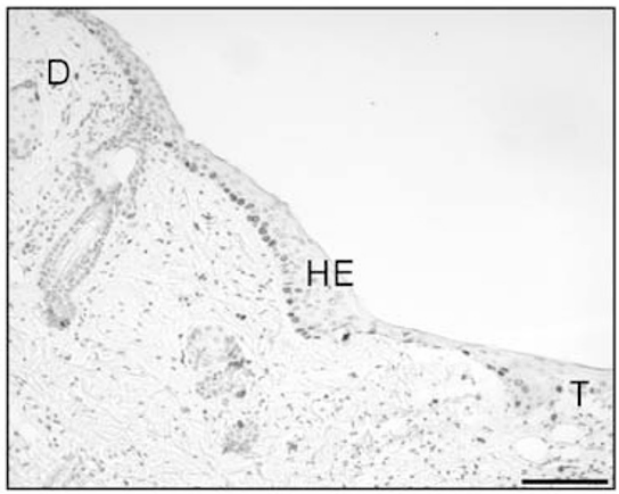

e
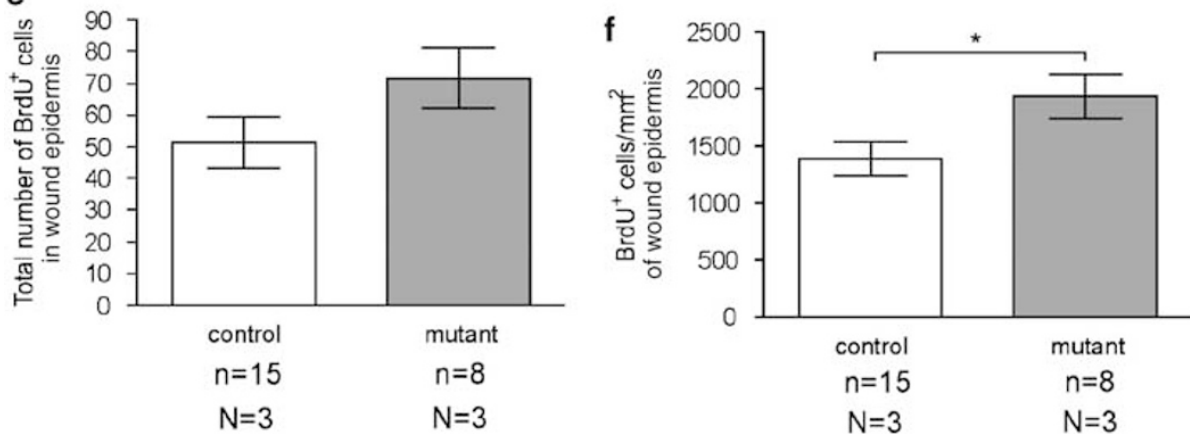

Figure 6 Increased proliferation of keratinocytes at the wound edge 3 days after wounding. (a, d) Detection of proliferating cells in the hyperproliferative epithelium 5 (a) and 3 days after wounding (d). HE: hyperproliferative epithelium; D: dermis; Es: eschar; T: tip of migrating epithelial tongue. Bar $=100 \mu$ m. $(\mathbf{b}, \mathbf{c}, \mathbf{e}, \mathbf{f})$ Quantification of proliferating cells in 5-day $(\mathbf{b}, \mathbf{c})$ and 3-day $(\mathbf{e}, \mathbf{f})$ wounds. The total number of BrdU-positive cells in the hyperproliferative epithelium ( $\mathbf{b}, \mathbf{e})$ and the number of BrdU-positive cells per area of hyperproliferative epithelium $(\mathbf{c}, \mathbf{f})$ are shown. $n=$ number of measurements; $N=$ number of mice $\left(\mathbf{c}:{ }^{\star} P=0.0499 ; \mathbf{f}:{ }^{\star} P=0.0421\right)$. Results shown are mean \pm s.e.m. 

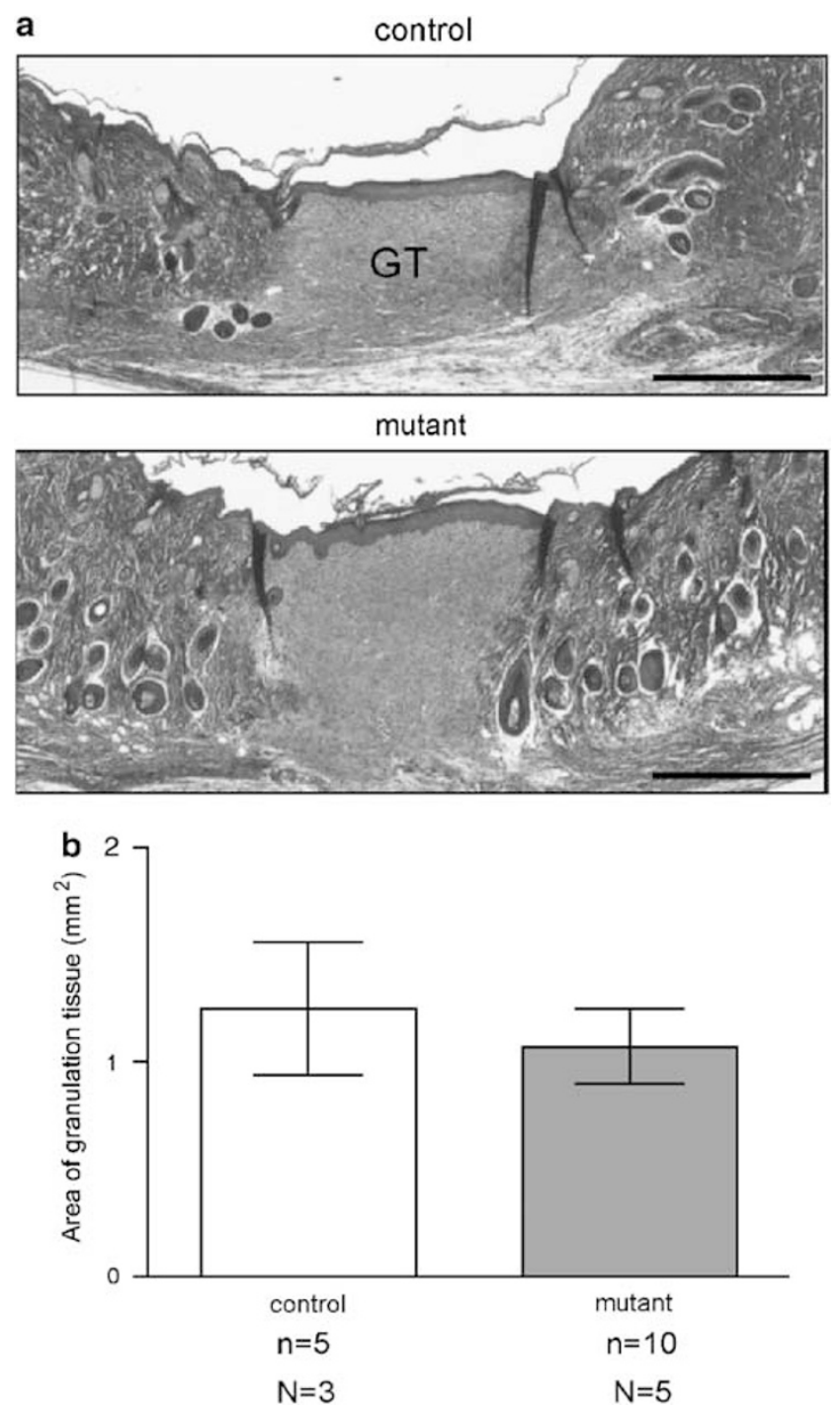

Figure 7 Reepithelialization, keratinocyte differentiation and granulation tissue formation are unaltered in Fst mutant mice 13 days after wounding. (a) Masson trichrome-stained histological sections of 13-day wounds (13 $\mathrm{dw}$ ) of control and mutant mice are shown. GT: granulation tissue. Bar $=500 \mu \mathrm{m}$. (b) The area of granulation tissue in $13 \mathrm{dw}$ is similar in control and mutant mice. $n=$ number of measurements; $N=$ number of mice. Results shown are mean \pm s.e.m.

\section{DISCUSSION}

In this study, we explored the consequences of keratinocytespecific ablation of the activin-binding protein Fst. Our findings revealed that Fst controls keratinocyte proliferation in the tail epidermis and in skin wounds. Most importantly, they suggest that limited activation of activin in keratinocytes is beneficial for the wound healing process.

It has previously been shown that the lack of Fst in all cell types causes epidermal hyperplasia in newborn mice. Surprisingly, this phenotype was not recapitulated in keratinocyte-specific Fst-null mice, suggesting that the phenotype is caused by the loss of Fst in stromal cells. This supports previous findings from our laboratory demonstrating a substantial impact of activin on keratinocyte proliferation by activation of stromal cells. In that study, expression of both activin and a dominant-negative activin receptor in keratinocytes of transgenic mice did not fully abrogate the hyperproliferative skin phenotype seen in mice, which only express the ligand. ${ }^{27}$ Further evidence for an indirect effect of activin on keratinocytes comes from cell culture experiments where activin stimulation did not affect proliferation of keratinocytes from control or Fst mutant mice (our unpublished observations) or even inhibited proliferation of keratinocytes. ${ }^{29}$ Although we cannot exclude the possibility that mesenchyme-derived Fst can compensate for the lack of this protein in keratinocytes, our previous findings mentioned above support the hypothesis of a double paracrine mechanism, where activin induces expression of factors in stromal cells, which in turn stimulate keratinocyte proliferation. However, the existence of such a mechanism is still speculative and the identity of the responsible factors remains to be determined.

In contrast to newborn skin, we observed hyperproliferation of keratinocytes in the tail epidermis of adult mutant mice. This phenotype reflects the abnormalities seen in activin-overexpressing mice ${ }^{11}$ and suggests that keratinocytederived Fst protects cells in the normal epidermis of adult mice from activin-mediated excessive proliferation. As activin does not stimulate proliferation of keratinocytes directly, this effect is most likely mediated through the underlying stroma (see above). This implies that endogenous activin can diffuse to the dermal compartment in the absence of keratinocyte-derived Fst. However, the extent of stromal cell activation in Fst mutant mice is obviously much less pronounced compared to mice overexpressing activin in the epidermis, as the hyperproliferative phenotype in the former is much less severe. Furthermore, strong fibrosis was observed in activin-overexpressing mice, ${ }^{11}$ but not in Fst mutant mice.

In addition to the phenotype seen in interfollicular tail epidermis, delayed hair follicle cycling had been found in activin-overexpressing mice. ${ }^{6}$ Although we also detected slight abnormalities in hair cycling in Fst mutant mice, the difference never reached statistical significance (data not shown). This is consistent with the observed downregulation of BMP-2 expression in activin-overexpressing mice, ${ }^{6}$ but not in the Fst mutant mice described in this study (data not shown).

The qualitatively similar phenotypes seen in Fst mutant mice and in activin-overexpressing mice strongly suggest that the major function of keratinocyte-derived Fst in normal skin is the inhibition of activin function. By contrast, inhibition of BMPs by Fst appears to be physiologically less relevant in the skin. This hypothesis is supported by the higher affinity of Fst for activins than for most BMPs. ${ }^{21,22,24,25,30}$ Furthermore, myostatin/GDF-8 is predominantly expressed in muscle tissue $^{31}$ and strongly downregulated in the skin after wounding (Figure 4), and GDF-11/BMP-11 is not expressed in normal 
or wounded skin (data not shown). In addition, expression of several BMPs, which are low-affinity binding partners of Fst, were downregulated upon wounding (Figure 4). Finally, the full rescue of the wound healing phenotype of activinoverexpressing mice by mating with Fst-overexpressing mice ${ }^{10}$ strongly suggests that Fst predominantly blocks activin action in normal and wounded skin.

The growth inhibitory effect of Fst for keratinocytes was particularly obvious in healing skin wounds, resulting in an earlier onset of keratinocyte proliferation and acceleration of reepithelialization during the first days after injury. This beneficial effect again recapitulates the phenotype seen upon overexpression of activin in keratinocytes. ${ }^{11}$ However, the latter revealed fibrosis in normal skin and strongly enhanced scarring after injury. This is consistent with the overexpression of activin in human hypertrophic scars and keloids. ${ }^{32,33}$ These negative consequences of activin overexpression were not observed in the Fst mutant mice described in this study. Thus, the free activin that is generated in the absence of keratinocyte-derived Fst is obviously insufficient to enhance granulation tissue formation and subsequent scarring. This may be because of the lower concentration of free activin compared to the activin-transgenic mice and/or to limited diffusibility. Therefore, limited activation of activin in the skin enhances the early phase of the wound healing process without inducing excessive scarring.

\section{ACKNOWLEDGEMENTS}

We thank Christiane Born-Berclaz, ETH Zurich, for excellent technical assistance. This work was supported by grants from the European Union (Ulcertherapy, LSHB-CT-2005-512102 to SW), the Swiss National Science Foundation (3100A9-109340/1 to SW) and the EMBO (WPF2004/22 fellowship to MA). The Fst-null and fl mutant mice were created with the support of National Institutes of Health grant HD32067 (to MMM).

1. Phillips DJ. The activin/inhibin family. In: Thomson AW, Lotze MT (eds) The Cytokine Handbook, 4th edn. Academic Press: London, 2003, pp 1153-1177.

2. Mathews LS. Activin receptors and cellular signaling by the receptor serine kinase family. Endocr Rev 1994;15:310-325.

3. Nakamura $\mathrm{T}$, Takio $\mathrm{K}$, Eto $\mathrm{Y}$, et al. Activin-binding protein from rat ovary is follistatin. Science 1990;247:836-838.

4. Chang H, Brown CW, Matzuk MM. Genetic analysis of the mammalian transforming growth factor-beta superfamily. Endocr Rev 2002;23 787-823.

5. Matzuk MM, Lu N, Vogel $\mathrm{H}$, et al. Multiple defects and perinatal death in mice deficient in follistatin. Nature 1995;374:360-363.

6. Nakamura M, Matzuk MM, Gerstmayer B, et al. Control of pelage hair follicle development and cycling by complex interactions between follistatin and activin. FASEB J 2003;17:497-499.

7. Lin SY, Craythorn RG, $\mathrm{O}^{\prime}$ Connor $A E_{\text {, et }}$ al. Female infertility and disrupted angiogenesis are actions of specific follistatin isoforms. Mol Endocrinol 2008:22:415-429.

8. Werner S, Alzheimer C. Roles of activin in tissue repair, fibrosis, and inflammatory disease. Cytokine Growth Factor Rev 2006;17:157-171.

9. Hubner $\mathrm{G}, \mathrm{Hu} \mathrm{Q}$, Smola $\mathrm{H}$, et al. Strong induction of activin expression after injury suggests an important role of activin in wound repair. Dev Biol 1996;173:490-498.

10. Wankell M, Munz B, Hubner G, et al. Impaired wound healing in transgenic mice overexpressing the activin antagonist follistatin in the epidermis. EMBO J 2001;20:5361-5372.

11. Munz B, Smola $H$, Engelhardt $F$, et al. Overexpression of activin $A$ in the skin of transgenic mice reveals new activities of activin in epidermal morphogenesis, dermal fibrosis and wound repair. EMBO 1999;18:5205-5215.

12. Ramirez A, Page A, Gandarillas A, et al. A keratin $\mathrm{K} 5 \mathrm{Cre}$ transgenic line appropriate for tissue-specific or generalized Cre-mediated recombination. Genesis 2004;39:52-57.

13. Jorgez CJ, Klysik M, Jamin SP, et al. Granulosa cell-specific inactivation of follistatin causes female fertility defects. Mol Endocrinol 2004; 18:953-967.

14. Werner $\mathrm{S}$, Smola $\mathrm{H}$, Liao $\mathrm{X}$, et al. The function of KGF in morphogenesis of epithelium and reepithelialization of wounds. Science 1994;266:819-822.

15. Chomczynski P, Sacchi N. Single-step method of RNA isolation by acid guanidinium thiocyanate-phenol-chloroform extraction. Anal Biochem 1987;162:156-159.

16. Werner $S$, Weinberg $W$, Liao $X$, et al. Targeted expression of a dominant-negative FGF receptor mutant in the epidermis of transgenic mice reveals a role of FGF in keratinocyte organization and differentiation. EMBO J 1993:12:2635-2643.

17. Rozen S, Skaletsky H. Primer3 on the WWW for general users and for biologist programmers. Methods Mol Biol 2000;132: 365-386.

18. Montanez E, Piwko-Czuchra A, Bauer M, et al. Analysis of integrin functions in peri-implantation embryos, hematopoietic system, and skin. Methods Enzymol 2007;426:239-289.

19. Wankell $M$, Kaesler $S$, Zhang $Y Q$, et al. The activin binding proteins follistatin and follistatin-related protein are differentially regulated in vitro and during cutaneous wound repair. J Endocrinol 2001;171:385-395.

20. de Winter JP, ten Dijke $P$, de Vries $C J$, et al. Follistatins neutralize activin bioactivity by inhibition of activin binding to its type II receptors. Mol Cell Endocrinol 1996;116:105-114.

21. Gamer LW, Wolfman NM, Celeste AJ, et al. A novel BMP expressed in developing mouse limb, spinal cord, and tail bud is a potent mesoderm inducer in Xenopus embryos. Dev Biol 1999;208: 222-232.

22. lemura S, Yamamoto TS, Takagi $C$, et al. Direct binding of follistatin to a complex of bone-morphogenetic protein and its receptor inhibits ventral and epidermal cell fates in early Xenopus embryo. Proc Natl Acad Sci USA 1998;95:9337-9342.

23. Amthor $\mathrm{H}$, Nicholas $\mathrm{G}$, McKinnell I, et al. Follistatin complexes myostatin and antagonises myostatin-mediated inhibition of myogenesis. Dev Biol 2004;270:19-30.

24. Schneyer AL, Sidis Y, Gulati A, et al. Differential antagonism of activin, myostatin and growth and differentiation factor 11 by wild-type and mutant follistatin. Endocrinology 2008;149:4589-4595.

25. Sidis $\mathrm{Y}$, Mukherjee $\mathrm{A}$, Keutmann $\mathrm{H}$, et al. Biological activity of follistatin isoforms and follistatin-like-3 is dependent on differential cell surface binding and specificity for activin, myostatin, and bone morphogenetic proteins. Endocrinology 2006;147:3586-3597.

26. Otsuka F, Moore RK, lemura $S$, et al. Follistatin inhibits the function of the oocyte-derived factor BMP-15. Biochem Biophys Res Commun 2001:289:961-966.

27. Bamberger $C$, Scharer $A$, Antsiferova $M$, et al. Activin controls skin morphogenesis and wound repair predominantly via stromal cells and in a concentration-dependent manner via keratinocytes. Am J Pathol 2005;167:733-747.

28. Gurtner GC, Werner S, Barrandon Y, et al. Wound repair and regeneration. Nature 2008;453:314-321.

29. Seishima $M$, Nojiri $M$, Esaki $C$, et al. Activin $A$ induces terminal differentiation of cultured human keratinocytes. J Invest Dermatol 1999;112:432-436.

30. Sidis Y, Tortoriello DV, Holmes WE, et al. Follistatin-related protein and follistatin differentially neutralize endogenous vs exogenous activin. Endocrinology 2002;143:1613-1624.

31. MCPherron AC, Lawler AM, Lee SJ. Regulation of skeletal muscle mass in mice by a new TGF-beta superfamily member. Nature 1997:387:83-90.

32. Fumagalli M, Musso $T$, Vermi W, et al. Imbalance between activin $A$ and follistatin drives postburn hypertrophic scar formation in human skin. Exp Dermatol 2007;16:600-610.

33. Mukhopadhyay A, Chan SY, Lim IJ, et al. The role of the activin system in keloid pathogenesis. Am J Physiol Cell Physiol 2007;292:C1331-C1338. 